\title{
Determination of nucleosides and nucleotides in seawater by HPLC; application to phosphatase activity in cultures of the alga Phaeocystis pouchetii*
}

\author{
Wim Admiraal ${ }^{* *}$ \& Marcel J. W. Veldhuis \\ State University of Groningen, Department of Marine Biology, PO Box 14, 9750 AA Haren, The Netherlands \\ and \\ Netherlands Institute of Sea Research, PO Box 59, 1790 AB Den Burg, Texel, The Netherlands
}

\begin{abstract}
Nucleosides and nucleotides, dissolved in artificial and natural seawater, were separated by HPLC (High Pressure Liquid Chromatography) on a C-18 reversed phase column. Test compounds in concentrations as low as 5 to $25 \mathrm{nM}$ were directly detectable by UV-absorption. Determinations of nucleosides and nucleosidemonophosphates were used to analyse the alkaline phosphatase activity (APA) in cultures of Phaeocystis pouchetii. Phosphate-depleted cultures of this colonial phytoplankter hydrolysed uridine mono-phosphate at a rate 7 times higher than 3-0-methylfluorescein phosphate, a commonly used artificial test substance for APA. The uridine, cytidine and guanosine moieties of nucleoside monophosphates were partially assimilated by the cultures, probably in connection with enzymatic hydrolysis. The application of HPLC analysis of cellular and dissolved nucleotides in both cultures and natural communities of planktonic organisms is discussed.
\end{abstract}

\section{INTRODUCTION}

The nucleotide ATP has been widely used to assess the biomass of communities of marine organisms, such as algae, bacteria and small animals (Holm-Hansen \& Booth 1966). This nucleotide forms an essential link in the energy metabolism of organisms and hence is a universal attribute of living cells, but it has also been detected in seawater in significant amounts as a free dissolved compound (Azam \& Hodson 1977). Analogously, Francko \& Wetzel $(1980,1982)$ demonstrated that C-AMP, a nucleotide with potential regulatory functions in cells, also occurs in culture media and lake water.

Karl (1980) and Cembella et al. (1983) pointed to the diversity of nucleotides present in aquatic organisms

- Publication No. 4 of the project 'Ecological Research of the North Sea' (EON). This investigation was supported by the Foundation for Fundamental Biological Research (BION), which is subsidized by the Netherlands Organization for the Advancement of Pure Research (ZWO).

- Present address: National Institute of Public Health and Environmental Hygiene, POB 1, 3720 BA Bilthoven, The Netherlands in addition to ATP, and indicated the many possibilities for using nucleotide ratios for fingerprinting the metabolism of aquatic organisms. An increasing number of radioactively-labelled nucleo-bases, (such as adenine; Craven \& Karl 1984), nucleosides (such as thymidine; Fuhrman \& Azam, 1982) and nucleotides (such as uridine triphosphate; Smith at al. 1985) are now being used to study macromolecular synthesis in communities of marine microorganisms. The in situ concentrations of all these compounds in seawater are largely unknown. To date, nucleotide determinations have relied almost exclusively on highly sensitive determinations by bioluminescence (cf. Karl \& Holm-Hansen 1978, Francko \& Wetzel 1982). Although it has been possible to adapt these determinations for several nucleotides (Karl 1980) an integrated chromatographic determination of several nucleotides would be highly desirable. Determinations of the (UV-detectable) nucleotides after HPLC separation have been developed for e.g. heart tissue (Burnette et al. 1983) and yeast cultures (Freese et al. 1984), whereas derivatized adenosines have been detected fluorometrically (Davis \& White 1980, Preston 1983).

The research described in this paper was part of a 
study that aims to measure a wide range of purine and pyrimidine nucleosides and nucleotides by HPLC. This technique was first used to measure the hydrolysis of nucleotides by alkaline phosphatase in cultures of the haptophycean alga Phaeocystis pouchetii. Our aim was to compare the kinetics of nucleotide hydrolysis with those of methylfluorescein phosphate, an artificial substance used for the in situ measurement of alkaline phosphatase activity.

\section{MATERIALS AND METHODS}

HPLC equipment. Chromatographic analysis was done on a HPLC (High Pressure Liquid Chromatography) system composed of a Waters 6000 pump, a Waters U6K injector and a Waters 440 absorption detector equipped with a filter set, selecting a wavelength of $254 \mathrm{~nm}$. In the absence of a peak integrator we quantified the separated compounds by measuring the peak height recorded on a line recorder.

Column, elution buffers, and chemicals. All the separations were carried out on a $25 \mathrm{~cm}$ long, $3.8 \mathrm{~mm}$ wide column of C-18 packing material (grain size $5 \mu \mathrm{m}$, Betatron). A guard-column, filled with C-18 Corasil (Waters) was used throughout and the columns were flushed with pure methanol from time to time to remove UV-absorbing material. The following 3 elution buffers were used: (I) $50 \mathrm{mM}$ ammonium phosphate ( $\mathrm{pH} 5.0$ ), prepared from reagent grade ammonia and phosphoric acid. Chromatographic conditions were analogous to those used by Hull-Ryde et al. (1983) for separating nucleotides. (II) as (I), but with $10 \%$ methanol (HPLC-quality, Rathburn). This eluant was used for separating nucleosides. (III) $92.5 \% 50$ $\mathrm{mM}$ ammonium phosphate buffer $(\mathrm{pH} 5.0)$ and $7.5 \%$ methanol $(\mathrm{v} / \mathrm{v})$, supplied with tetrabuthylammoniumchloride (TBA, Merck) to a final concentration of $1 \mathrm{mM}$. TBA served as a very effective ion-pair for nucleotides. The addition of TBA to elution buffers was found to be effective in separating desoxyribonucleosides and their monophosphates (cf. Caronia et al. 1983).

Nucleosides and nucleotides were obtained from Sigma Co. and were kept in frozen stock solutions of 1 $\mathrm{mg} \mathrm{ml} \mathrm{m}^{-1}$.

Fluorometric test of phosphatase activity. The hydrolysis of 3-0 methylfluorescein phosphate (Sigma) was measured according to Perry (1972). The concentration of methylfluorescein phosphate used ranged from 50 to $1330 \mathrm{nM}$. The product, methylfluorescein, was measured on a Baird fluoricord spectrofluorometer, calibrated with commercially obtained methylfluorescein (Sigma). Alkaline phosphatase from calf intestine (Boehringer) was used for comparison.

Cultures of Phaeocystis pouchetii. Cultures of
Phaeocystis pouchetii were grown in synthetic seawater with a low phosphate level $(1.5 \mu \mathrm{M})$. Such cultures exhibited a characteristic development, whereby some of the single cells initially present formed colonies when the phosphate in the medium was exhausted. As a result, high activities of alkaline phosphatase were measured for both cell types (Veldhuis \& Admiraal 1987). Mixed phosphate-deprived cultures with ca $50 \%$ single cells and ca $50 \%$ colony cells were used in the present experiments and were incubated at $13^{\circ} \mathrm{C}$.

The Phaeocystis pouchetii cultures contained low numbers of bacteria $\left(10^{7} 1^{-1}\right)$, despite efforts to isolate axenic strains. However, the cell concentration of $P$. pouchetii exceeded that of the contaminating bacteria by a factor of ca 5 , and the biovolume of the $P$. pouchetii population was 2000 times larger than that of the contaminating bacterial population.

Nucleotides and nucleosides were determined in culture medium of Phaeocystis pouchetii after $5 \mathrm{ml}$ of culture had been rapidly filtered through a $0.2 \mu \mathrm{m}$ membrane filter (Gelman, Acrodisc).

\section{RESULTS}

\section{Outline of the separation}

Fig. 1 shows the separation of a series of nucleosides and nucleotides, dissolved in distilled water after elution without (A) and with (B) the ion-pair TBA. Elution A resulted in distinct peaks of most compounds, eluting in the first $15 \mathrm{~min}$. In Fig. 1A the uridine-containing compounds have been omitted even though peaks could be discerned for all individual compounds. On the other hand a distinct peak of NAD was recorded as late as ca 60 min after injection (not shown). Elution $B$ resulted in a more homogeneous chromatogram in which only ATP and C-AMP were strongly retarded.

\section{Direct injection of seawater}

Nucleosides and nucleotides dissolved in seawater were also successfully separated; however, a front of UV-absorbing material preceded the chromatogram (Fig. 2).

Fig. 2 shows the elution profiles of nucleosides and nucleoside monophosphates not affected by the injection of 25 to $125 \mu$ l seawater (or culture medium). The largest injected volume used (125 $\mu$ ) had only a slightly negative effect on the separation of CMP and UMP, which have a very low retention time. Some of the nucleosides (cytidine, uridine, guanosine and probably thymidine) were equally well separated in 
Fig. 1. Elution of nucleotides and nucleosides, dissolved in distilled water. Column: C-18 Detection: UV-absorption at $254 \mathrm{~nm}$ (0.1 a.u.f.) (A) $500 \mathrm{ng}$ per substance injected; elution at $0.7 \mathrm{ml} \mathrm{min} \mathrm{min}^{-1}$ with $50 \mathrm{mM} \mathrm{NH}_{4} \mathrm{PO}_{4}$-buffer, $\mathrm{pH} 5.0$ (code I). (B) $825 \mathrm{ng}$ per substance injected; elution at $1.4 \mathrm{ml} \mathrm{min}^{-1}$ with $1 \mathrm{mM}$ TBA in a mixture of $92.5 \%$ of the $\mathrm{NH}_{4} \mathrm{PO}_{4}$-buffer (pH 5.0) and $7.5 \%$ methanol (code III)

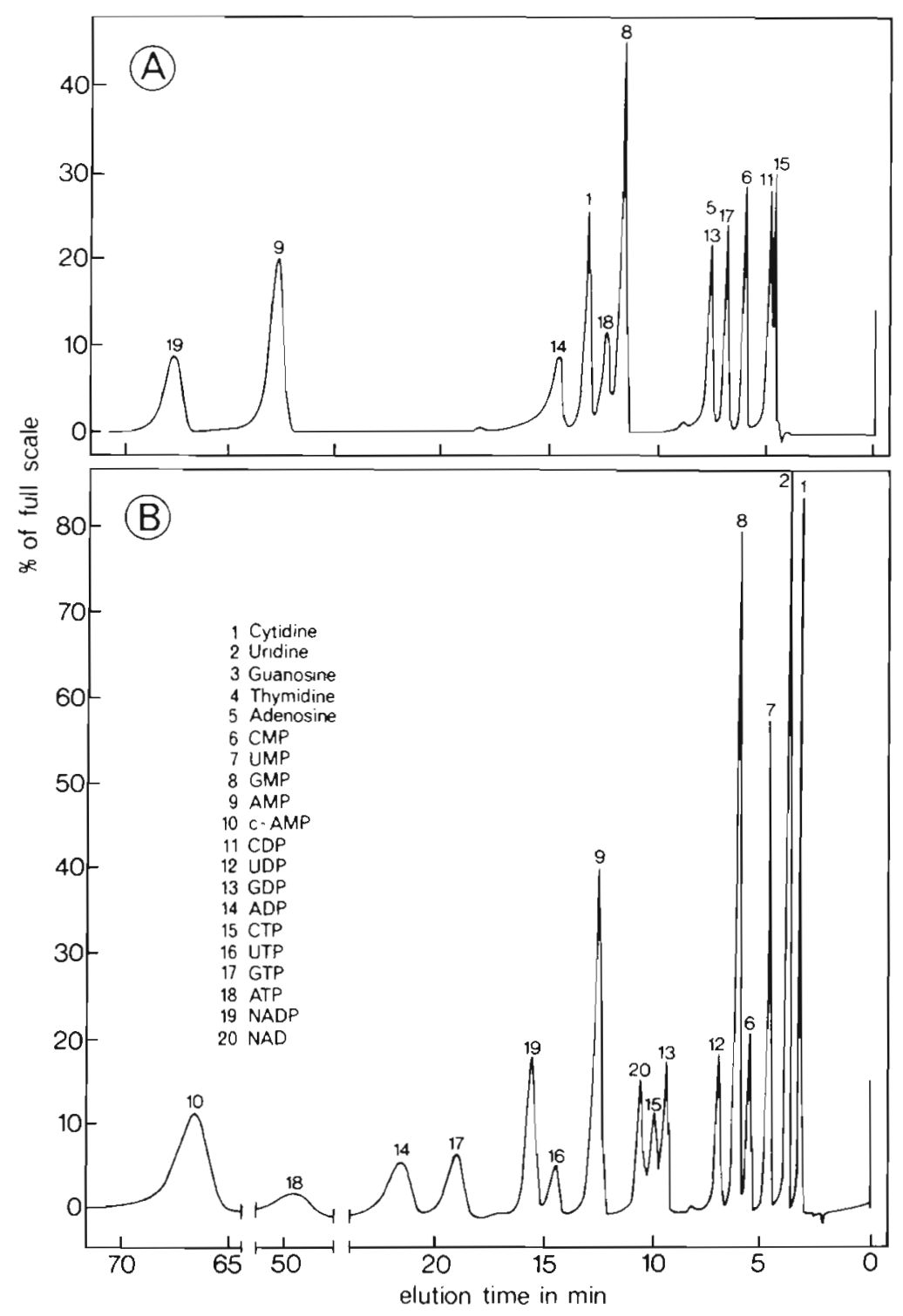

Run A, which was selected for monophosphates; this observation is exploited in experiments described later.

The injection of $25 \mu \mathrm{l}$ of seawater disturbed the pattern obtained with TBA-equilibrated columns; nevertheless, the 4 triphosphates tested were fully separated (result not shown).

\section{Quantification and detection limits}

Fig. 3 shows the calibration of nucleosides and nucleoside monophosphates, separated with 2 modifications of the eluant. The relation between added concentration and peak height is linear over the concentration intervals of 25 to $1000 \mathrm{nM}$. The detection limit of some compounds (such as GMP and uridine) was lower than $10 \mathrm{nM}$, whereas for the other compounds this limit was between 10 and $25 \mathrm{nM}$. Under certain conditions the detection limits may be lowered further by increasing the injected volume to more than $125 \mu \mathrm{l}$ and using the detector's full sensitivity of 0.005 a.u.f.

\section{Phosphatase activity, measured by fluorometry and by HPLC}

A commercially available preparation of alkaline phosphatase was used to test the enzymatic hydrolysis of a nucleotide (UMP) using the HPLC analysis described earlier. Uridine monophosphate (with uridine as a product) was chosen for convenience, 

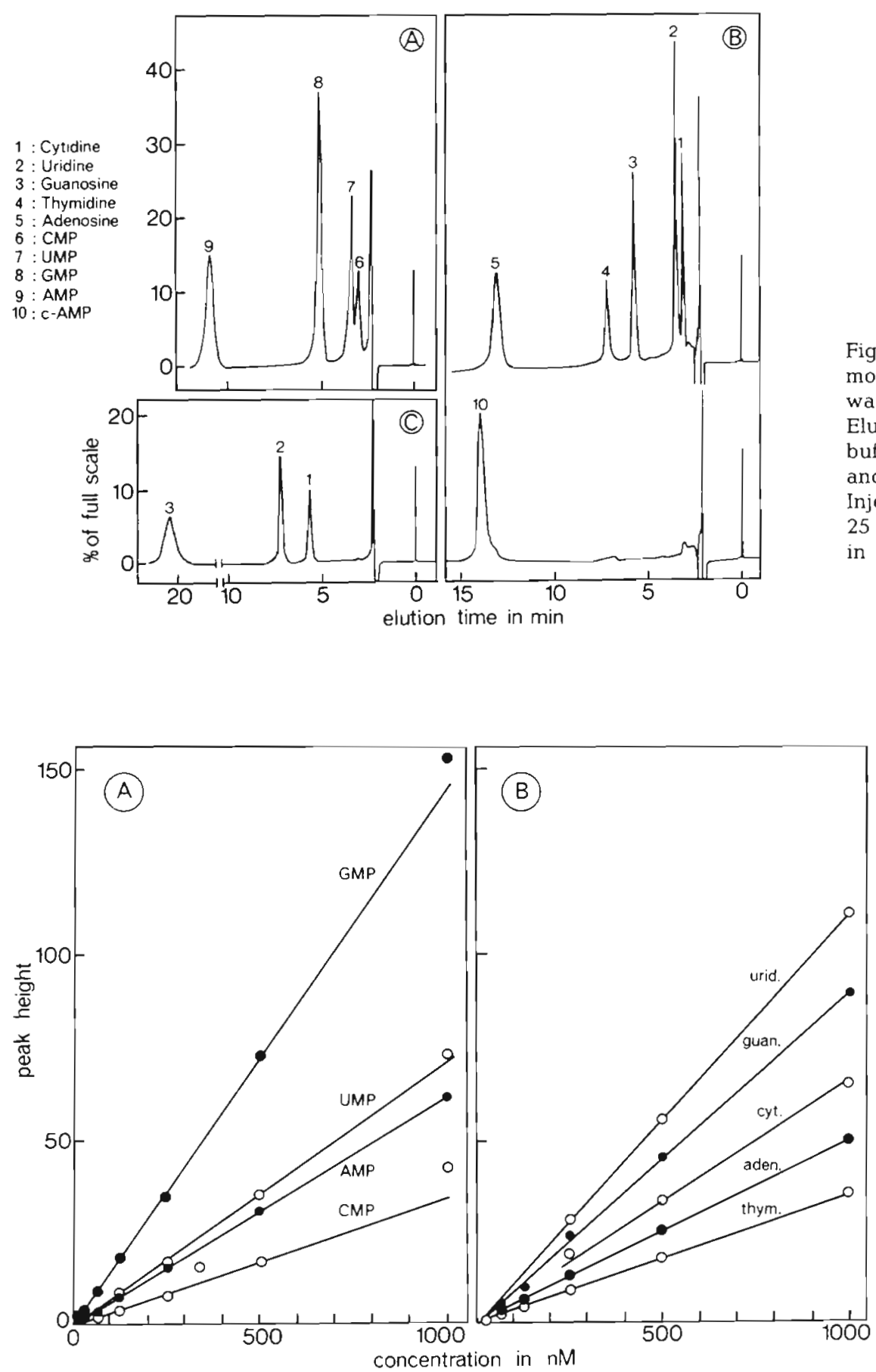

Fig. 2. Elution of nucleosides and nucleoside monophosphates, dissolved in artificial seawater. Detection: UV $254 \mathrm{~nm}$ (0.01 a.u.f.) Elution of $(\mathrm{A})$ and $(\mathrm{C})$ : with $50 \mathrm{mM} \mathrm{NH}_{4} \mathrm{PO}_{4}$ buffer, pH 5.0 (code I). Elution of (B): as (A) and (C), but with $10 \%$ methanol (code II). Injected volume in (A): $125 \mu \mathrm{l}$, in (B) and (C): $25 \mu \mathrm{l}$. Concentration in sample (A): $500 \mu \mathrm{M}$; in samples (B) and (C): $2500 \mathrm{nM}$ per substance
Fig. 3. Calibration of nucleoside monophosphates eluted with buffer I (A), and of nucleosides eluted with buffer II (B). Injected volume: $125 \mu$ ] of synthetic seawater. Detection: UV $254 \mathrm{~nm}$ (0.01 a.u.f.) because the HPLC analyses of these 2 compounds could be completed within $8 \mathrm{~min}$. With slight modifications the other monophosphates can be used equally well and the time needed for the HPLC analysis could be reduced further.

Fig. 4 shows that the hydrolysis of UMP could be recorded as well by the disappearence of UMP as by the formation of uridine. The hydrolysis of methylfluorescein phosphate proceeded at a rate ca $50 \%$ higher than that of UMP expressed per unit enzyme. Although it required longer incubation times than needed for the extremely sensitive determination with the fluorometer at full sensitivity, the HPLC method seemed to be equally effective. 
Fig. 4. Comparison of alkaline phosphatase activity (from calf intestine), measured (A) by the hydrolysis of methylfluorescein phosphate; (B) by the reduction of the UMP concentration (O) or by the formation of uridine ( $\square$ ), determined by HPLC. Incubation (A) contained 0.186 enzyme units per $100 \mathrm{ml}$; incubation (B) contained 0.559 enzyme units. Initial concentration of substrate in (A) and (B): $200 \mathrm{nM}$

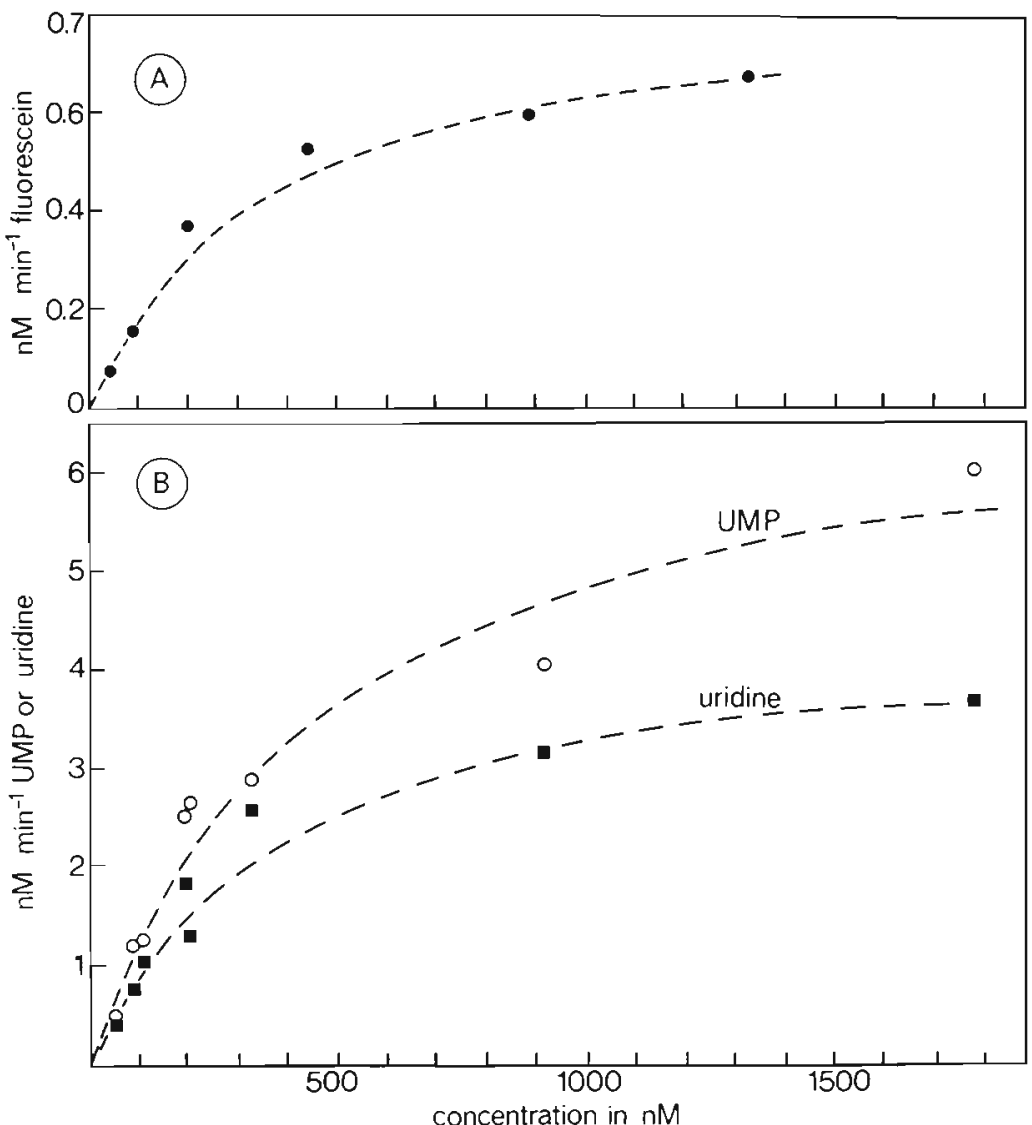

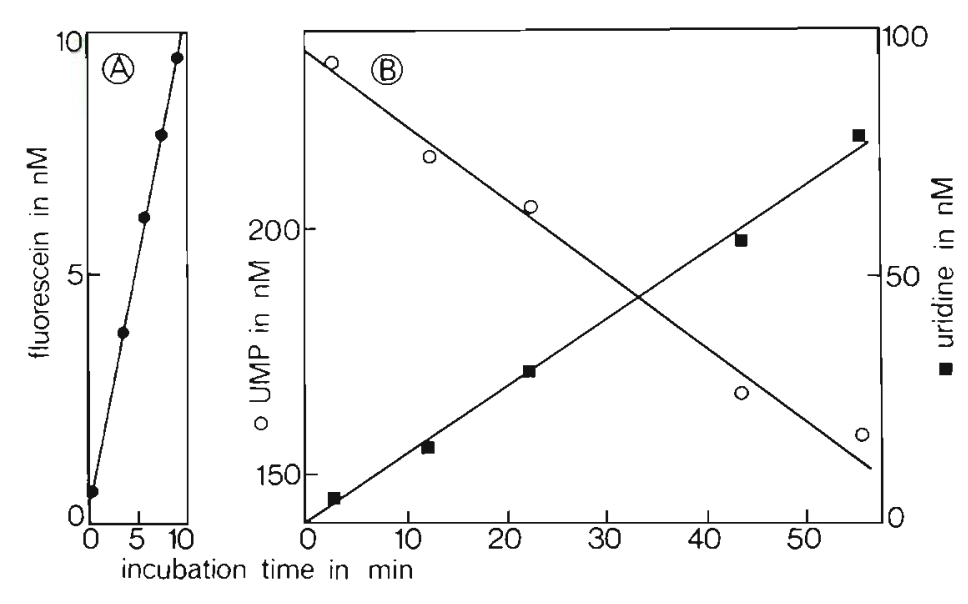

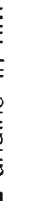

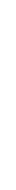

Fig. 5. Phaeocystis pouchetii. Saturation of alkaline phosphatase activity in cultures, measured with methylfluorescein phosphate (A) and with UMP (B). In $(B)$, rates measured by the decrease in UMP (O) and rates determined by the formation of uridine ( $\square$ ). Note the different vertical scales in (A) and (B) 
caused by deficient calibration of these substances, because the effect was not observed in cell-free incubations (Fig. 4). Since uridine added to Phaeocystis pouchetii cultures (see later results) was not assimilated, it seems likely that the disappearance of uridine is closely connected with the hydrolysis of UMP at the cell surface (see later observations).

\section{Hydrolysis of nucleotides in Phaeocystis pouchetii cultures}

The potential hydrolysis or uptake of several nucleotides in phosphate-deficient cultures of Phaeocystis pouchetii was measured by adding them in high con- centrations of $2500 \mathrm{nM}$ and recording their breakdown over several hours. Table 1 shows that CMP, UMP, GMP and AMP were degraded simultaneously, but the pyrimidin-containing compounds seem to be hydrolysed at a slightly higher rate than the purines. The parallel production of nucleosides again indicated that a minor part of the uridine was lost upon hydrolysis. The same effect also occurred for guanosine and was even stronger for cytidine. However, none of these nucleosides was assimilated clearly when added in $2500 \mathrm{nM}$ concentration to the culture (Table 1).

Triphosphates and C-AMP diminished after several hours of incubation in the cultures, but their degradation proceeded at a lower rate than observed for the non-cyclic monophosphates.

Table 1. Phaeocystis pouchetii. Hydrolysis of nucleotides in phosphate-depleted cultures. Four incubations, numbered I, II, III and IV, contained respectively 4 monophosphates, 4 triphosphates, 5 nucleosides and cyclic AMP, in initially high concentrations of $2500 \mathrm{nM}$

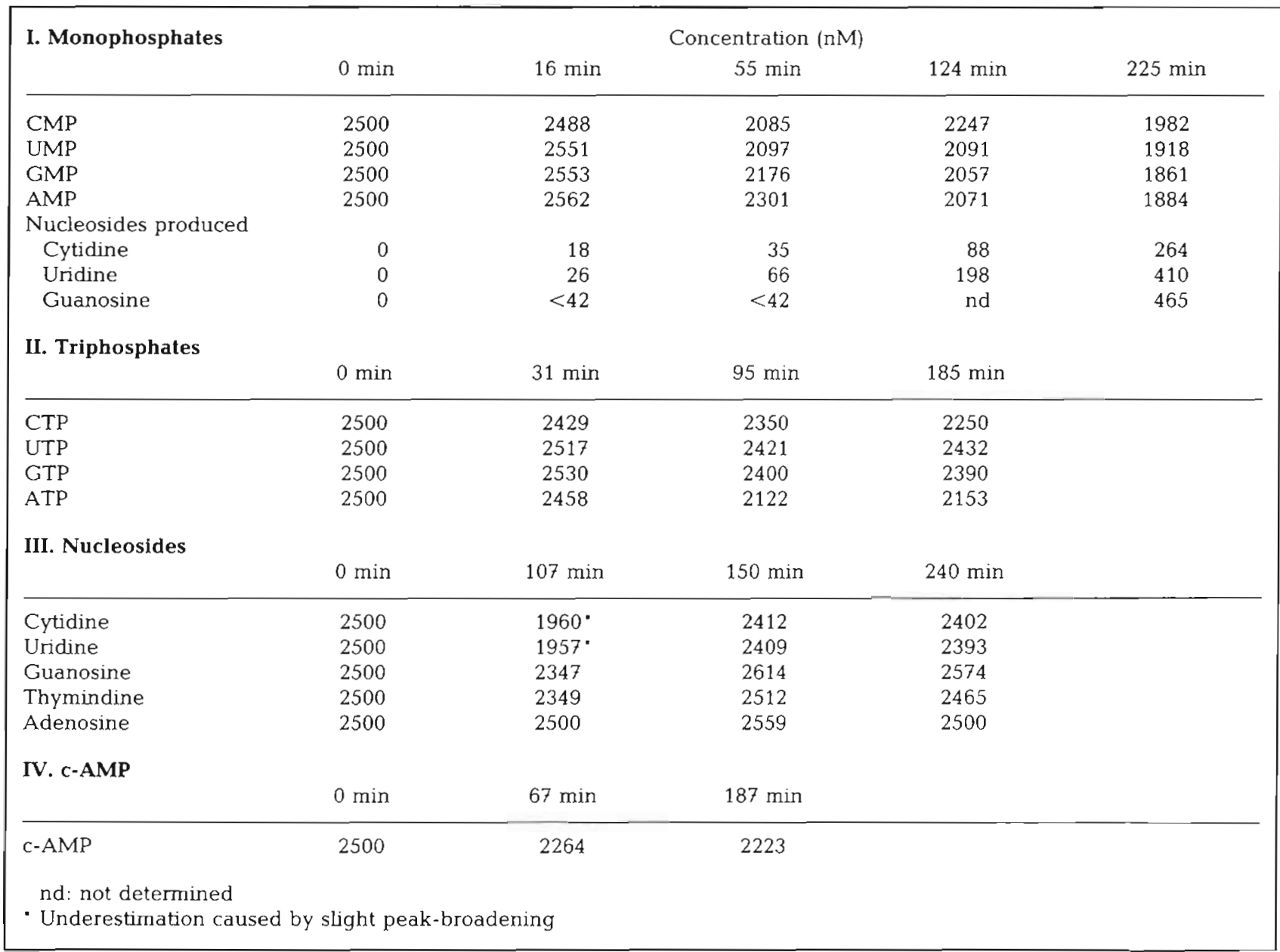




\section{DISCUSSION}

\section{Action spectrum of alkaline phosphatase}

Cembella et al. (1983) cautioned against the use of 'unnatural' test substrates in measuring the phosphate monoesterase activity in microalgae. The action spectrum of phosphatases in several microorganisms towards phosphate esters can be very different. Cembella's warning is substantiated by our observations on the phosphatase activity in Phaeocystis pouchetii which show that a nucleoside monophosphate is hydrolysed much more rapidly than the artificial test substrate methylfluorescein phosphate, whose use, e.g. in field studies, may severely underestimate the monoesterase (phosphatase) activity.

High concentrations of nucleotide monophosphates as well as of phosphorylated sugars are suitable sources of phosphate in cultures of many algal species (for references see Cembella et al. 1983). Now that we have shown that nucleosides and nucleoside monophosphates can be analysed in seawater and culture media by HPLC, it seems possible to bridge the gap between culture studies (which use an extremely high concentration of organic phosphates) and the situation in the sea where phosphatase activity is commonly observed (cf. Perry 1976, Møller et al. 1975, Veldhuis unpubl.).

Karl \& Craven (1980) demonstrated that the alkaline phosphatase activity in microbial communities in the sea might easily affect the cellular levels of nucleotides measured after extraction. Francko \& Wetzel (1982) found a positive relation between phosphatase activity and C-AMP levels in lake phytoplankton and lake water. Further information on the action spectrum of the phosphatase in the plankton would therefore seem to be desirable.

Ammerman \& Azam (1985) demonstrated the importance of a bacterial enzyme, 5'-nucleotidase, which hydrolyses ATP in seawater. This enzyme activity differs in the following ways from the algal phosphatase activity found in the present study: (1) half-saturation values of 3 to $67 \mathrm{nM}$ instead of ca $400 \mathrm{nM}$; (2) maximum rates of hydrolysis 0.06 to $4.07 \mathrm{nM}$ per litre of seawater per hour, whereas cultures and natural populations of Phaeocystis pouchetii (Veldhuis unpubl.) were able to hydrolyse organic phosphates at 100-fold higher rates; (3) a selectivity for ATP, whereas $P$, pouchetii cultures hydrolysed several other compounds; (4) insensitivity to orthophosphate: Veldhuis \& Admiraal (1987) found that the very high phosphatase activities in $P$. pouchetii were highly sensitive to additions of orthophosphate.

These differences suggest that the hydrolysis of organic phosphates in the cultures of Phaeocystis pouchetii was indeed dominated by the algal phos- phatase and was hardly affected by any $5^{\prime}$-nucleotidase present in the low numbers of contaminating bacteria.

\section{Importance of organic phosphorus to Phaeocystis pouchetii}

The pool of dissolved organic phosphates in the sea is largely unidentified. The discrimination into orthophosphate (soluble reactive phosphates), organic phosphates (liberated after chemical hydrolysis) and complexes of orthophosphate is problematic. Taft et al. (1977) and Kobori \& Taga (1979) measured the organic phosphates that were subject to enzymatic degradation. This hydrolysable organic phosphate is probably the relevant fraction for phytoplankton that rely on their cell surface phosphatases for the use of organic phosphate. The concentrations observed in coastal waters were in the order of $10 \mathrm{nM}$ (Taft et al. 1977) or 100 nM (Kobori \& Taga 1979). Phaeocystis pouchetii is found in abundant blooms that coincide with phosphate depletion (concentrations less than $0.08 \mu \mathrm{M}$ soluble reactive phosphate; Veldhuis et al. 1986). At that time organic phosphate may be also important to the organism, as a source of $P$. Therefore the kinetics of orthophosphate uptake and hydrolysis of organic phosphates are of decisive importance. $P$. pouchetii was able to assimilate orthophosphate at a maximum rate of $8.7 \times 10^{-6} \mathrm{nmol} \mathrm{cell-1} \mathrm{h}^{-1}$ (Table 2; Veldhuis et al. unpubl.) Nucleoside monophosphates were hydrolysed at similar rates, although hydrolysis of organic phosphate does not assure the immediate use of the orthophosphate liberated. The $\mathrm{K}_{\mathrm{S}}$ for hydrolysis of organic phosphates was even lower than for orthophosphate uptake (Table 2). Hence, in the ecologically interesting concentration range below $100 \mathrm{nM}$ (cf. Kobori \& Taga 1979, Taft et al. 1977) added organic monophosphates were processed twice as rapidly as

Table 2. Phaeocystis pouchetii. Kinetic constants for hydrolysis of methylfluorescein phosphate, uridine monophosphate (UMP) and for uptake of orthophosphate in 3 cultures (a, b, and c). NMP: mixture of 4 nucleoside monophosphates including UMP

\begin{tabular}{|lccc|}
\hline Substrate & Reference & $\begin{array}{c}\mathrm{V}_{\max } \\
\left(10^{-6} \mathrm{nmol}\right. \\
\left(\mathrm{cell}^{-1} \mathrm{~h}^{-1}\right)\end{array}$ & Ks (nM) \\
\hline a. Fluor. P & Unpublished & 0.78 & 250 \\
b. Fluor. P & Fig. 5 & 0.65 & 360 \\
UMP & Fig. 5 & 4.63 & 450 \\
C. NMP & Table 1 & 9.48 & - \\
Orthophosphate & Veldhuis unpubl. & 8.7 & 800 \\
\hline
\end{tabular}


the same concentration of orthophosphate. This observation provides further support for the views expressed earlier that utilization and/or reutilization of organic phosphates by marine microalgae is a quantitatively important process (cf. Cembella et al. 1983).

\section{Analysis of cellular and dissolved nucleotides; perspectives for HPLC}

The technical difficulties associated with the measurement of nucleosides and nucleotides in natural seawater and marine organisms are tremendous and it will not be attempted here to reiterate the excellent reviews on the subject given by Karl (1980) and Cembella et al. (1983, 1984). Little is known about the in situ concentrations of free dissolved nucleosides and nucleotides in aquatic habitats, other than for ATP (Azam \& Hodson 1977), and c-AMP (Ammerman \& Azam 1981, Francko \& Wetzel 1982). ATP concentrations reached up to $1 \mathrm{nM}$ in coastal waters and cAMP occasionally reached values of a few nM in lake water (Francko \& Wetzel 1982), but was much lower, 1 to $35 \mathrm{pM}$, in seawater (Ammerman \& Azam 1981). Radioactive thymidine and the nucleo-base adenine were added to water samples to study macromolecular synthesis of micro-organisms (Fuhrman \& Azam 1982, Craven \& Karl 1984), although the in situ concentration of these compounds was unknown. The saturation of the uptake of the compounds by additions of a few nM suggests that their initial concentrations were in the order of magnitude of $1 \mathrm{nM}$ or less. The present HPLC method had a detection limit of $5 \mathrm{nM}$ for some of the directly injected compounds, which is only slightly higher than the detection limits published for ethenoadenosine derivatives detected fluorometrically ( 2 to 5 pmol per injection: Davis \& White $1980 ; 1$ to $2 \mathrm{nM}$ : Preston 1983). Both the present direct determination and the fluorometric determination (of adenosines) lack the sensitivity for direct analysis of seawater. This may not be a real obstacle for further research. Even for the highly sensitive determination of ATP and C-AMP by biolunimescence it is necessary to purify the samples either on charcoal (Azam \& Hodson 1977) or ion exchangers (Francko \& Wetzel 1980). Group separation of nucleotides and nucleosides on a silica column has been reported by Lohtrop \& Uziel (1980), so that obtaining purified and 10 to 100 -fold concentrated samples of nucleotides from seawater seems feasible. Once these sample pre-treatments are realized, the full range of nucleotides in seawater can be measured by HPLC.

Concentration seems to be less of a problem in the determination of cellular nucleotides. Cursory observations showed that cell extracts contained the adenosine mono-, di-, and triphosphate, and high concentrations of NAD and NADP. However, the high concentrations of UV-absorbing material in these extracts may also make a purification step necessary, so that the nucleotides present in low concentrations can be detected. The problems involved may not be very different from those already explored for nonmarine organisms (Burnette et al. 1983, Freese et al. 1984). Here, the speed of sample collection and the effectiveness of sample extraction pose the main problems. Therefore the application of HPLC may widen the study of cellular nucleotides in phytoplankton, a line of research begun by Holm-Hansen \& Booth (1966).

Acknowledgements. A discussion on the application of HPLC with Dr. P. Williams (Millipore Corp.) is gratefully acknowledged. Mrs J. Burrough-Boenisch correted the English text.

\section{LITERATURE CITED}

Ammerman, J. W., Azam, F. (1981). Dissolved cyclic adenosine monophosphate (CAMP) in the sea and uptake of cAMP by marine bacteria. Mar. Ecol. Prog. Ser. 5: 85-89

Ammerman, J. W., Azam, F. (1985). Bacterial 5'-nucleotidase in aquatic ecosystems: a novel mechanism of phosphorus regeneration. Science 227: 1338-1340

Azam, F., Hodson, R. E. (1977). Dissolved ATP in the sea and its utilization by marine bacteria. Nature, Lond. 267: 696-698

Burnette, B., McFarland, C. R., Batra, P. (1983). Rapid isocratic separation of purine nucleotides using strong anionexchange high-performance liquid chromatography. J. Chromat. 277: 137-144

Caronia, J. P., Crowther, J. B., Hartwick, R. A. (1983). Reversed-phase sepasation of the major desexyribonucleosides and their mononucleotides using tetrabutylammonium hetaerons. J. Liquid Chromat. 6: 1673-1691

Cembella, A. D., Antia, N. J., Harrison, P. J. (1983). The utilization of inorganic and organic phosphorus compounds as nutrients by eukaryotic microalgae: a multidisciplinary perspective: Part 1. CRC crit. Rev. Microbiol. 10: 317-391

Cembella, A. D., Antia, N. J., Harrison, P. J. (1984). The utilization of inorganic and organic phosphorus compounds as nutrients by eukaryotic microalgae: a multidisciplinary perspective: Part 2. CRC crit. Rev. Microbiol. 11: 13-81

Craven, D. B., Karl, D. M. (1984). Microbial RNA and DNA synthesis in marine sediments. Mar. Biol. 83: 129-139

Davis, W. M., White, D. C. (1980). Fluorometric determination of adenosine nucleotide derivatives as measures of the microfouling, detrital, and sedimentary microbial biomass and physiological status. Appl, environ. Microbiol. 40: $539-548$

Francko, D. A., Wetzel, R. G. (1980). Cyclic adenosine-3':5'monophosphate: production and extra cellular release from green and blue-green algae. Physiologia pl. 49: $65-67$

Francko, D. A., Wetzel, R. G. (1982). The isolation of cyclic adenosine $3^{\prime}: 5^{\prime}$-monophosphate (cAMP) from lakes of different trophic status: correlation with planktonic metabolic variables. Limnol. Oceanogr. 27: 27-38 
Freese, E., Olempska-Beer, Z., Eisenberg, M. (1984). Nucleotide composition of cell extracts analysed by full-spectrum recording in high-performance liquid chromatography. J. Chromat. 284: 125-142

Fuhrman, J. A., Azam, F. (1982). Thymidine incorporation as a measure of heterotrophic bacterioplankton production in marine surface waters: evalution and field results. Mar. Biol. 66: 109-120

Holm-Hansen, O., Booth, C. R. (1966). The measurements of adenosine triphosphate in the ocean and its ecological significance. Limnol. Oceanogr. 11: 510-519

Hull-Ryde, E. A., Cummings, R. G., Lowe, J. E. (1983). Improved method for high energy nucleotide analysis of canine cardiac muscle using reversed-phase high-performance liquid chromatography. J. Chromat. 275: 411-417

Karl, D. M. (1980). Cellular nucleotide measurements and applications in microbial ecology. Microb. Rev. 44: 739-796

Karl, D. M., Craven, D. B. (1980). Effects of alkaline phosphatase activity on nucleotide measurements in aquatic microbial communities. Appl. environ. Microbiol. 40: 549-561

Karl, D. M., Holm-Hansen, O. (1978). Methodology and measurement of adenylate energy charge ratios in environmental samples. Mar. Biol. 48: 185-197

Kobori, H., Taga, N. (1979). Phosphatase activity and its rôle in the mineralization of organic phosphorus in coastal sea water. J. exp. mar. Biol. Ecol. 36: 23-39

Lohtrop, C. D., Uziel, M. (1980). Rapid group seperations of nucleotides and related compounds on silica columns.
Analyt. Biochem. 109: 160-166

Møller, M., Myklestad, S., Haug, A. (1975). Alkaline and acid phosphatases of the marine diatoms Chaetoceros affinis var. willei (Gran) Hustedt and Skeletonema costatum (Grev.) Cleve. J. exp. mar. Biol. Ecol. 19: 217-226

Perry, M. J. (1972). Alkaline phosphatase activity in subtropical Central North Pacific waters using a sensitive fluorometric method. Mar. Biol. 15: 113-119

Perry, M. J. (1976). Phosphate utilization by an oceanic diatom in phosphorus-limited chemostat culture and in the oligotrophic waters of the central North Pacific. Limnol. Oceanogr. 21: 88-107

Preston, M. R. (1983). Determination of adenine, adenosine and related nucleotides at the low picomole level by reversed-phase high performance liquid chromatography with fluorescence detection. J. Chromat. 275: 178-182

Smith, J. C., Platt, T., Li, W. K. W., Horne, E. P. W., Harrison, W. G., Subba Rao, D. V., Irwin, B. D. (1985). Arctic marine photoautotrophic picoplankton. Mar. Ecol. Prog. Ser. 20: $207-220$

Taft, J. L., Loftus, M. E., Taylor, W. R. (1977). Phosphate uptake from phosphomonoesters by phytoplankton in the Chesapeake Bay. Limnol. Oceanogr. 22: 1012-1021

Veldhuis, M. J. W., Colijn, F., Venekamp, L. A. H. (1986). The spring bloom of Phaeocystis pouchetii (Haptophyceae) in Dutch coastal waters. Neth. J. Sea Res. 20: 37-48

Veldhuis, M. J. W., Admiraal, W (1987). The influence of phosphate depletion on the growth and colony formation of Phaeocystis pouchetii (Hariot) Lagerheim. Mar. Biol. (in press) 